\title{
Enhanced Third Order Nonlinear Optical Properties of Methyl Orange Dye Doped Potassium Penta Borate Octa Hydrate (MOPPB) Single Crystals Using CW Diode Laser for Optical Limiting Applications
}

K Kamatchi ( $\sim$ kamatchi.k11@gmail.com)

SASTRA Deemed University: Shanmugha Arts Science Technology and Research Academy https://orcid.org/0000-0003-2864-6834

\section{S. Sriram}

SASTRA University School of Electrical and Electronics Engineering: Shanmugha Arts Science Technology and Research Academy School of Electrical and Electronics Engineering

\section{K. Sangeetha}

SASTRA University SEEE: Shanmugha Arts Science Technology and Research Academy School of

Electrical and Electronics Engineering

E. Anuranjani

SASTRA University School of Electrical and Electronics Engineering: Shanmugha Arts Science

Technology and Research Academy School of Electrical and Electronics Engineering

\section{Durairaj}

Bharathidasan University

\section{T.C.Sabari Girisun}

Bharathidasan University

\section{Research Article}

Keywords: Single crystal study, FTIR, Micro Hardness study, Z-scan study and optical limiting behavior

Posted Date: February 17th, 2021

DOl: https://doi.org/10.21203/rs.3.rs-204816/v1

License: (c) (i) This work is licensed under a Creative Commons Attribution 4.0 International License. Read Full License 


\title{
Enhanced Third Order Nonlinear Optical Properties of Methyl Orange Dye Doped Potassium Penta Borate Octa Hydrate (MOPPB) Single Crystals Using CW Diode Laser for Optical Limiting Applications
}

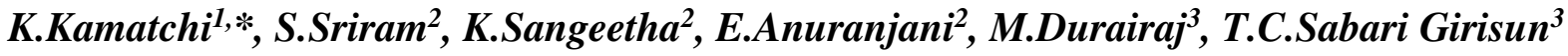 \\ ${ }^{1}$ Department of Physics, SASTRA Deemed University, SRC, Kumbakonam, TamilNadu India \\ ${ }^{2}$ Department of Physics, SEEE, SASTRA Deemed University, Thanjavur, TamilNadu, India \\ ${ }^{3}$ Nanophotonics Laboratory, Department of Physics, Bharathidasan University, Tiruchirappalli, \\ TamilNadu, India
}

\begin{abstract}
Single crystals of pure (PPB) and methyl orange dye doped Potassium Penta Borate octa hydrate (MOPPB) are grown by slow evaporation technique at ambient conditions. Single crystal $\mathrm{X}$-Ray Diffraction study verifies the orthorhombic family of both pure and MO doped PPB crystals. FTIR assures the incorporation of MO dye into PPB crystals. The Reverse Indentation Size Effect (RISE) behavior and soft nature of both pure and MO doped PPB crystals are verified by the Micro Hardness Study. Absorbance studies shows PPB possess lower cut-off wavelength at $190 \mathrm{~nm}$ due to $\pi-\pi^{*}$ transitions whereas MOPPB crystals have two peaks, one at $278.60 \mathrm{~nm}$ due to $\pi-\pi^{*}$ transitions and the second one at $464.65 \mathrm{~nm}$ due to $\mathrm{n}-\pi^{*}$ transitions. The inclusion of MO dye molecules alters the band structure resulting in reduction of bandgap to $5.7 \mathrm{eV}$ (MOPPB) from $5.91 \mathrm{eV}$ (PPB). Kurtz powder test shows green emission in both pure PPB and MOPPB with relative SHG efficiency of 0.45 times and 0.40 times that of SHG output of KDP. Z-scan studies performed with $785 \mathrm{~nm}$ laser excitation exposes that both pristine and MO doped PPB crystal exhibit reverse saturable nonlinear absorption and self-focusing nonlinear refraction which is thermo-optic in origin. Two photon absorption induced optical limiting action is demonstrated in both PPB and MOPPB crystals. Increase in NLO coefficient due to MO dye confirms the superiority of MOPPB than PPB for optical limiting applications.
\end{abstract}

Key Words: Single crystal study, FTIR, Micro Hardness study, Z-scan study and optical limiting behavior. 


\section{Introduction}

Nowadays, nonlinear optical (NLO) materials are overwhelmingly explored because of their dynamic and vibrant applications in telecommunications, optical switching, optical modulation, 3-D optical memory devices, optical limiters etc., [1]. For the past three decades, these NLO materials are attracting the scientific community for the generation of short wavelength lasers using second and third harmonic generation phenomenon [2-4]. With horizon of laser wavelength expanding very rapidly, one alarming fact of laser is that they can easily damage photosensitive components including human eyes [5]. So in recent years, utilization of organic NLO materials are no longer limited to production of laser through harmonic generation, but also in addressing the solution for laser accidents [6-8]. Laser safety devices that functions on NLO phenomenon are generally called as optical limiters which exhibits transparency at low powers and turns opaque at high incident intensities. Regardless of the input power magnitude, these optical limiters are designed to maintain irradiance, power, fluence or energy transmitted by an optical system below some specified maximum value. Fabrication and testing the performance of optical limiters made of organic, inorganic and semiorganic materials are under recent limelight. Among them, organic azo dyes are interesting as they possess broad spectral response and high nonlinear absorption coefficients. Azo dyes contain organic compounds which contain the colouring agent $(\mathrm{N}=\mathrm{N})$ possessing the functional group $\mathrm{R}-\mathrm{N}=\mathrm{N}-\mathrm{R}$ ' where $\mathrm{R}$ ' and $\mathrm{R}$ are aryl groups. When these dyes are doped into the host materials, they show improved nonlinear optical absorption phenomena such as Saturable Absorption (SA), Reverse Saturable Absorption (RSA), etc., [9-10]. In the choice of host material, inorganic borates such as Potassium Penta Borate octa hydrate (PPB) are potential candidate as they possess high mechanical and thermal stability along with high NLO coefficients [11-14]. PPB is basically a transparent material and is highly transparent to visible region. Hence addition of organic dyes like Methyl orange (MO) can avail interesting visible absorption to the host and these change in band structure can influence the nonlinear absorption behavior of the system [15-20]. Methyl Orange dyes find wide applications in light emitting diodes, organic semiconductors, photo voltaic devices, thermal printing, biology, medical fields as wound healing, photo dynamic therapy, pharmaceutical chemistry, etc., [21]. Also the chromophore of MO shows excellent nonlinear optical behavior especially Reverse Saturable Absorption [9-10]. The molecular structure of Methyl Orange is shown in Fig. (1). This article reports the preparation and characterization of pure (PPB) and methyl orange doped potassium penta borate (MOPPB) for the 
optical limiting applications for the first time. Under CW Diode laser of $785 \mathrm{~nm}$ wavelength excitation, both the materials exhibit optical limiting action exposing their suitability for laser safety devices.

\section{Crystal Growth and Structural Confirmation}

Commercially available Potassium Penta borate octa hydrate $\left(\mathrm{B}_{10} \mathrm{H}_{16} \mathrm{~K}_{2} \mathrm{O}_{24}\right)$ and Methyl Orange $\left(\mathrm{C}_{14} \mathrm{H}_{14} \mathrm{~N}_{3} \mathrm{NaO}_{3} \mathrm{~S}\right)$ were taken for the reaction. Saturation point at room temperature was noted to grow the pure PPB single crystals. For MOPBB the doping concentration was taken in the ratio of 1:0.05M. $\mathrm{pH}$ of both pure PPB and MOPPB solutions were maintained at 7 and 5, respectively. After 4 hours of vigorous stirring both the solutions were filtered and sealed with perforated sheet and left undisturbed for slow evaporation at ambient condition. Fig.2 (a) \& (b) shows the harvested pure and MO doped PPB single crystals after a period of 35 and 45 days, respectively. The pristine crystals and doped PPB were subjected to single Crystal X-ray Diffraction (XRD) studies using an ENRAF NONIUS CAD4 X-Ray Diffractometer with a MoK $K_{\alpha}$ radiation $(\lambda=0.71073 \AA)$. The unit cell parameters for pure PPB and MO doped PPB are tabulated

in Table 1. The obtained results were in good agreement with reported literature [22]. It was also clear from the changes seen in the unit cell parameter and volume that MO entered successfully into the crystal lattice of the parent material without any change in the crystal structure.

Molecular structure and the functional group associated with grown crystals were identified by Perkin-Elmer Fourier Transform Infrared (FTIR) spectrometer. The recorded FTIR spectra of pure and MO doped PPB crystals are shown in Fig. 3 and it gives the necessary information about the molecular arrangements of the crystals. The strong and broad band associated with the stretching vibrations of the hydroxyl group with strong hydrogen bonding appears at $3444 \mathrm{~cm}^{-1}$ [23]. Also, the peak at $3378 \mathrm{~cm}^{-1}$ is due to the $\mathrm{O}-\mathrm{H}$ stretching vibrations [24]. The $\mathrm{C}-\mathrm{H}$ stretching vibration is characterized at $3062 \mathrm{~cm}^{-1}$ [25]. The $\mathrm{C}-\mathrm{H}$ stretching mode vibrations due to MO appear at $2669 \mathrm{~cm}^{-1}$ [18]. The peak at $1844 \mathrm{~cm}^{-1}$ is due to the stretching vibrations of CO band [26]. $\mathrm{NH}_{2}$ in plane deformations are characterized at $1653 \mathrm{~cm}^{-1}$ and $1434 \mathrm{~cm}^{-1}$ [27]. The peak at $1358 \mathrm{~cm}^{-1}$ is due to $\mathrm{C}-\mathrm{CH}$ in-plane deformations [28]. The $\mathrm{B}-\mathrm{O}$ stretching vibrations of $\mathrm{BO}_{3}$ is confirmed by the peak at $920 \mathrm{~cm}^{-1}$. Moreover the wagging of $\mathrm{N}-\mathrm{H}$ vibrations are confirmed from the peaks at $782 \mathrm{~cm}^{-1}, 765 \mathrm{~cm}^{-1}$ and $734 \mathrm{~cm}^{-1}[29]$. OBO terminal bending and ring bending vibrations are 
assured by the peaks at $590 \mathrm{~cm}^{-1}$ and $508 \mathrm{~cm}^{-1}$. The spectral band assignments of MO doped PPB crystals are shown in Table 2.

\section{Mechanical Stability}

Mechanical stability of the crystals was tested under Vickers Microhardness Tester (Shimadzu HMV-2). Both PPB and MOPPB crystals were subjected to three loads 25, 50 and 100 $\mathrm{g}$ and the corresponding hardness value were plotted. Also, the direct variation of stress and strain relating to the stiffness constant can be calculated from the Wooster's relation [30-32]. The Vicker's Hardness number can be calculated using the formula $H_{V}=\frac{1.8544 P}{d_{2}} \mathrm{~kg} / \mathrm{mm}^{2}$. Measure of Hardness value could easily say the measure of resistance to the permanent deformation or damage. This mechanical stability of the grown bulk material depends on structure, lattice energy, binding energy, interatomic spacing and Debye temperature. Also, it is closely related to the elastic constants, yield strength and stiffness constant [22]. From Fig. 4, it can be observed that the hardness number gradually increases with the applied load. Both pure PPB and MOPPB show the increase of hardness number with applied load thereby proving the Reverse Indentation Size Effect (RISE) [30]. On doping PPB with MO there was a clear improvement in the hardness number. This is because, MO dye being a large molecule gets filled up in the voids of the PPB crystal structure resulting in a compact lattice. The deforming capacity of both the crystals was observed to decrease on increasing loads above $100 \mathrm{~g}$ which resulted in crack formation. Heavier load dislocates the lattice and cracks are developed on the crystal surface. The Meyer's index for Pure PPB is 1.6 and that of MOPPB is 2 . Hence, both the crystals belong to the soft nature and can be utilized for laser safety devices.

\section{Linear optical study}

The absorption and the transmission spectra of PPB and MOPPB were studied between wavelengths 200-1200 nm using Perkin-Elmer UV-visible spectrometer. The optical bandgap of both pure PPB and MOPPB crystals can be calculated by the following formula $E_{g}=\frac{1.243 \times 10^{3}}{\lambda_{\max }}$. The inter and intra molecular hydrogen bonding between the Methyl Orange dye and the $\mathrm{OH}$ groups in the host molecule PPB could be easily identified by the UV-Vis absorption spectroscopic studies. The recorded transmission spectra of pure PPB and MOPPB crystals are shown in Fig. 5. From the figure, the lower cut-off wavelength of pure PPB was found at $190 \mathrm{~nm}$ [22] due to $\pi-\pi^{*}$ 
transitions whereas MOPPB crystals have two peaks, one at $278.60 \mathrm{~nm}$ due to $\pi-\pi *$ transitions and the second one at $464.65 \mathrm{~nm}$ due to $n-\pi^{*}$ transitions [33]. This confirms the addition of host molecule in the parent material. It is known that the MO dye contains one azo group and two phenyl rings. This azo group acts as a bridge between two phenyl rings and the OH-BO groups of the borate molecule [20]. This modifies the optical properties of the PPB crystals. Hence the inclusion of MO dye molecules introduces the additional energy levels between the valence band and conduction bands [20-21]. Because of this the bandgap of MOPPB crystals is decreased to 5.7 $\mathrm{eV}$ from $5.91 \mathrm{eV}$ which is for pure $\mathrm{PPB}$. Hence, alteration in band structure along with change in visible absorption is observed in MOPPB crystals.

\section{Nonlinear Optical Behavior}

\subsection{SHG Study}

Kurtz-Perry Technique was equipped to study the second harmonic generation employing the Q-Switched Nd:YAG laser of wavelength 1064 nm. In the SHG Study, Potassium Dihydrogen Phosphate (KDP) was taken as a reference whose SHG signal output was $70 \mathrm{mV}$. The recorded output of pure and MO doped PPB crystals were found to be about $32 \mathrm{mV}$ and $28 \mathrm{mV}$ respectively. Thus, Pure PPB is 0.45 times and MO doped PPB is 0.40 times that of SHG output of KDP. The decrease in output of MO doped from that of pure PPB might be due to the self-absorption of the input $532 \mathrm{~nm}$ wavelength by the doped material itself [24]. This can be well correlated readily by the absorption peak at $532 \mathrm{~nm}$ wavelength from the Fig. 5. Hence we could clearly observe that doping of MO in PPB shows some serious changes in the SHG efficiency.

\subsection{Z-Scan and Optical Limiting Study}

The nonlinear absorption (NLA) and nonlinear refraction (NLR) along with third order NLO susceptibility of pure PPB and MO doped PPB were determined from open aperture (OA) and closed aperture (CA) Z-scan experiment respectively. The continuous wave laser beam with 785 $\mathrm{nm}$ wavelength having peak power of $50 \mathrm{~mW}$ was focused and passed through the grown material. The sample was moved on the sample stage from the source to the detector along the direction of beam propagation. The transmittance of the beam was recorded at far-field for various positions of the sample with and without aperture infront of the detector. Then the graph was drawn between the transmittance and position of the sample. In general, nonlinear absorption arises due to various phenomenon like saturable absorption (SA), reverse saturable absorption (RSA) that originates 
from two photon absorption (2PA), multiphoton absorption (MPA), excited state absorption (ESA) or free carrier absorption (FCA)[36]. Here, valley-like OA curve (Fig. 7) of pure and MO doped PPB exposes the existence of reverse saturable absorption (RSA). To validate the observed nonlinearity and identify the mechanism responsible for nonlinear absorption, the experimental data were fitted with the theoretical equations given in Sheik-bahae formalism for an open aperture, $T_{n P A}=1 /\left[1+(n-1) \beta_{n} L\left(\frac{I_{0}}{1+\left(\frac{z}{z_{0}}\right)^{2}}\right)^{n-1}\right]^{\frac{1}{n-1}}$, where, $\beta_{n}$ is the nonlinear absorption coefficient, $n$ is order of the nonlinear absorption $(\mathrm{n}=1,2,3 \ldots), L$ is the effective thickness of the sample, $I_{0}$ is the incident intensity of the laser beam at the focal point and $\left(z_{0}=\frac{\pi \omega_{0}^{2}}{\lambda}\right)$ is the Rayleigh length[37]. The theoretical plots (solid line) matched very well with the experimental fits (solid circle) for two photon absorption equation. Thus both pure and MO doped PPB crystals exhibit two-photon absorption. Here as the mode of excitation is CW, observed nonlinearity is mostly thermo-optic in origin. And the presence of near-resonant energy states close to excitation wavelength have created sequential 2PA involving thermally induced excited state absorption. And, the closed aperture (CA) technique reveals about the negative or positive lens resulting in self-defocusing or self-focusing behaviour of the sample. Here, the prepared sample shows the self-focusing behaviour i.e. pre-focal valley followed by post-focal peak indicating the nonlinearity of the sample to be a positive lensing effect due to thermal effect. Theoretical validation of experimental data was made by fitting the theoretical normalized transmittance using the relation for closed aperture, $T_{C A}=1 \pm 4 \Delta \emptyset\left(\frac{z}{z_{0}}\right) /\left[1+\left(\frac{z}{z_{0}}\right)^{2}\right]\left[9+\left(\frac{z}{z_{0}}\right)^{2}\right]$ where, $\Delta \emptyset$ is the phase distortion of the transmitted laser beam due to refraction. Estimated nonlinear absorption coefficient $(\boldsymbol{\beta})$, nonlinear refractive index $\left(\mathrm{n}_{2}\right)$, third-order NLO susceptibility of pure PPB and MO doped PPB are summarized in Table 4. 2PA coefficient, nonlinear refractive index and thirdorder NLO susceptibility of MOPPB is higher than PPB which assured the superiority of azo dye incorporation in PPB crystals.

By optical limiting measurement, the critical power of the laser beam at which the nonlinearity starts to affect the transmission can be measured. Optical Limiting (OL) curves illustrated in Fig. 8 were extracted from the corresponding open aperture (OA) Z-scan data. The position-dependent fluence was calculated from the equation $\mathrm{F}(\mathrm{z})=\left(4 \sqrt{\ln 2} E_{\text {in }} / \pi^{3 / 2} \omega(z)^{2}\right)$, 
where $\mathrm{F}(\mathrm{z})$ is the fluence, $E_{\text {in }}$ is the incident laser energy, $\boldsymbol{\omega}_{\mathrm{o}}$ is the beam waist of the laser beam at the focus. The observed reverse saturable absorption and self-focusing could be attributed to the optical limiting behaviour of the pure PPB and MOPPB crystals. The onset optical limiting thershold of PPB and MOPPB is $0.843 \times 10^{-6} \mathrm{~J} / \mathrm{m}^{2}$ and $0.832 \times 10^{-6} \mathrm{~J} / \mathrm{m}^{2}$ respectively. Thus MOPPB stands superior than pure PPB for optical limiting applications which includes the safeguard of optical components from laser damages.

\section{Conclusions}

Good quality crystals of Pure and MO dye doped PPB crystals were grown by slow evaporation technique. Both crystals exhibited the orthorhombic nature and small change in lattice parameters confirms the inclusion of MO dye into PPB crystal structure. PPB and MOPPB show the increase of hardness number with applied load (RISE) and soft nature of the material. On doping PPB with MO there was a clear improvement in the hardness number because, larger MO dye the voids of the PPB crystal structure resulting in a compact lattice. Red shift in cut-off wavelength shifts from UV region $(190 \mathrm{~nm})$ to visible region $(465 \mathrm{~nm})$ in MOPPB crystal ascertains the inclusion of MO dye in PPB. Decrease in bandgap of PPB $(5.91 \mathrm{eV})$ due to MO incorporation in MOPPB $(5.7 \mathrm{eV})$ crystals is because azo group acts as a bridge between two phenyl rings and the OH-BO groups of the borate molecule. Relative SHG efficiency of pure PPB and MOPPB is 0.45 times and 0.40 times that of SHG output of KDP. OA Z-scan studies performed with $785 \mathrm{~nm}$ laser excitation exposed that crystals exhibit reverse saturable absorption due to two-photon absorption. Here the presence of near-resonant energy states close to excitation wavelength created sequential 2PA involving thermally induced excited state absorption. CA Zscan studies exposed that the prepared sample possess self-focusing behavior due to thermos-optic origin. 2PA coefficient, nonlinear refractive index and third-order NLO susceptibility of MOPPB is higher than PPB which assured the superiority of azo dye incorporation in PPB crystals. The observed two-photon absorption and self-focusing could be attributed to the optical limiting behaviour of the pure PPB and MOPPB crystals with onset optical limiting thershold of $0.84 \times 10^{-}$ ${ }^{6} \mathrm{~J} / \mathrm{m}^{2}$ and $0.83 \times 10^{-6} \mathrm{~J} / \mathrm{m}^{2}$ respectively. Thus MOPPB stands superior than PPB for optical limiting applications which includes the safeguard of optical components from laser damages.

\section{Acknowledgement:}


The author is grateful to SAIF-IIT, Chennai for providing the Single Crystal XRD. Also, the thanks are to St.Joseph's College, Tiruchirappalli for UV, FTIR and Microhardness studies. The author's sincere thanks are to Bharadhidasan University, Tiruchirapalli for Z-scan study and extends to Bangalore IISC, for SHG facility.

\section{References:}

[1]. Pritula, V. Gayvoronsky, Yu. Gromov, M. Kopylovsky, M. Kolybaeva, V. Puzikov,A. Kosinova, Funct. Mater. 15 (2008) 561-568.

[2]. Rajesh NP, Kannan V, Ashok M, et al. A new nonlinear optical semi-organic material: cadmium thio urea acetate. J Cryst Growth. 2004;262:561-566

[3]. Xue D, Zhang S. Effect of hydrogen bonds on optical non linearities of inorganic crystals, chemical. Physics Letters.1999;301(5-6):449-452.

[4]. Yu D, Xue D, Ratajczak H. Bond-valence parameters for characterizing O- H2O hydrogen bonds in hydrated borates. J MolStruct. 2006;792:280-2851

[5]. D. Sliney, M. Wolbarsht, Optical Radiation Hazards to the Skin. Safety with Lasers and Other Optical Sources, Springer Publications, Boston, MA 1980

[6]. D.S. Chemla, J. Zyss, Non-linear Optical Properties of Organic Molecules and Crystals, Academic Press, Orlando, New York,1987.

[7].N.J. Long, Organometallic compounds for nonlinear optics - the search for enlightenment, Angew. Chem. Int. Ed. Engl. 34 (1995)21-38

[8].T. Verbiest, S. Houbrechts, M. Kauranen, K. Clays, A.Persoons, Second-order nonlinear optical materials: recent advances in chromophore design, J. Mater. Chem. 7 (1997)2175-2189.

[9]. H. Yadav, N. Sinha, N. Tyagi B. Kumar, Cryst. Growth Des. 2015, 15,4908.

[10]. S. K. Chandran, R. Paulraj, P. Ramasamy, Mater. Res. Bull. 2015, 68,210.

[11]. K.Kamatchi and T.Radhakrishnan. Synthesis, Optical, Thermal and Microhardness Studies of L-Alanine Potassium Penta Borate Octa Hydrate (LAPPB). Journal of Applied Sciences 2014.1670-1673.DOI:10.3923/jas.2014.1670.1673. 
[12]. K.Kamatchi, S.Gopinath and T.Radhakrishnan. Thermal, Spectral and Mechanical Analysis of Glycine Potassium Penta Borate Octa Hydrate (GPPB) crystal.. International Journal of Chem Tech Research. Coden(USA:IJCRGG ISSN:0974-4290 Vol.7 No.01,pp 408-411 2014-15

[13]. K.Kamatchi, T.Radhakrishnan, A Potentially Useful Semiorganic Nonlinear optical Material L-Asparagine Potassium Penta Borate Octa Hydrate (Lasppb) for Opto- Electronic Device fabrication. International Journal of Chem Tech Research Coden(USA): IJCRGG ISSN:09744290 Vol.8 no.8 pp 227-233, 2015.

[14]. K.Kamatchi, P.Umarani, .T.Radhakrishnan, C.RamaChandraRaja, Investigation on OrganicInorganic Hybrid NLO Material L-Valine Potassium Penta Borate octa hydrate (LVPPB) for NLO Applications Optik, Vol.172,pp 674-679 http://doi.org/10.1016/j.ijleo.2018.07.054

[15]. Balaji Srikanth Ragunath, Kumaran Sangeetha and Ramraj Ramesh Babu, Reverse Saturable Absorption and Optical limiting Application of methyl orange dye doped L-Arginine Mono hydrochloride $\quad(\mathrm{LAHCl}) \quad$ Single $\quad$ Crystals www..crt-journal.org https://doi.org/10.1002/crat.201900190

[16]. R. Kayalvizhi, G. Meenakshi, S. Thiyagaraj, V. J. Priyadharshini, M. Indhumathi Growth And Characterisation Of Pure And Methyl Orange Doped Potassium Dihydrogen Phosphate (Kdp)Crystal International Journal of Advanced Science, Engineering and Technology. Vol 1, Issue 2, 2012, pp 39-42 http://www.bipublication.com

[17]. T. Raguram, K. S. Rajni, P. Shanmugam, S. Meiyazhagan Synthesis and Characterisation of Undoped and Methyl Orange (Dye)doped L-Alanine Acetate Single Crystal International Journal of Chem Tech Research CODEN (USA): IJCRGG, ISSN: 0974-4290, ISSN(Online):24559555Vol.9, No.07 pp 678-687, 2016

[18]. A.Kanagavalli, T.Seethalakshmi, J.Thomas Joseph PrakashJ. Martin Sam Gnanaraj Growth And Characterization Of Methyl Orange Doped Kap Crystals - A Potential Material For Optical And Second Harmonic Generation Applications International Journal of Research in Pharmaceutical and Nano Sciences. 5(3), 2016, 164 - 175. ISSN: 2319 - 9563 
[19]. D.Narayanasamy, P.Kumaresan, P.M.Anbarasan Effect of Dyes on TGS Crystals for IR Detector Applications International Journal of Advanced Research in Physical Science (IJARPS) Volume 2, Issue 1, January 2015, PP 19-24 ISSN 2349-7874 (Print) \& ISSN 2349-7882

[20]. Mahasin F. Hadi Al-kadhemy et.al, The effect of (He-Ne) laser irradiation on the optical properties of methyl orange doped PVA films Journal of Radiation Research and Applied Sciences http://dx.doi.org/10.1016/j.jrras.2014.05.006

[21]. M.Nageshwari, P.Jayaprakash, C.Rathika, ThangaKumari,G,vinitha, M.Lydia Caroline, Growth, Spectral, Linear and Non-linear Optical Characteristics of an Efficient semiorganic Acentric Crystal: L-Valinium L-Valine Chloride Physica B:Physics of Condensed Matter, DOI:http://dx.doi.org/10.10161 j.physb.2017.01.027

[22]. Saranraj Arumugam et.al Investigation on the impact of xylenol orange dye on the growth and properties of unidirectional grown KDP crystals for photonic applications Journal of Crystal Growth 523 (2019) 125154https://doi.org/10.1016/j.jcrysgro.2019.125154

[23]. R.Arivuselvi, P.RameshBabu, Investigation of inorganic nonlinear optical potassium penta borate tetra hydrate (PPBTH)Single crystals grown by Slow Evaporation Method. Physica B:Physics of Condensed Matter(2018).Doi:10.1016/j.physb.2017.12.051

[24]. T.Balakrishnan, G.Bagavannarayana, K.Ramamurthi Growth, Structural, Optical, thermal and Mechanical Properties of Ammonium Penta Borate single crystals. Spectra Chimica Acta PartA 71(2008)578-583

[25]. R.N.Jayaprakash, P.Kumaradass, Growth and Characterization of Urea L-valine An organic Non Linear Optical Crystal. Oriental Journal of Chemistry,ISSN;0970-CODEN;OJCHEG 2018,Vol,29,No(4) 020X Pg.1409-1414

[26]. S.Moitra. and T.Kar, Growth and Characterization of L-Valine-a Non Linear Optical Crystal. Crystal Res. Technology 45, No.1,70-74(2010)/DOI:10.1002/Crat 200900447.

[27]. K. Vikram, Rajib Nandi, Ranjan K. Singh, Spectrochim. Acta Part A Mol. Biomol. Spectrosc. 112 (2013) 377-383.

[28]. H.G. Brittain, Vibrational spectroscopic studies of cocrystals and salts, J. Cryst. Growth Des. 11 (2011) 2500-2509. 
[29]. A.N.Vigneshwaran ,A.Antony Joseph, C.Ramachandra Raja. A Study on the Properties of Potassium Penta Borate Crystals. Optik 127(2016) 5365-5369

[30]. K. Sangwal, Mater. Chem. Phys. 2000, 63, 145.

[31]. E. M. Onitsch, Mikroskopie1947, 2, 131.

[32]. W. A. Wooster, Rep. Prog. Phys. 1953, 16, 62.

[33]. J. Del Nero,R. E. de Araujo,A. S. L. Gomes and C. P. de Melo Theoretical and experimental investigation of the second hyper polarizabilities of methyl orange. The Journal of Chemical Physics 122, 104506 s2005

[33]. S.Jeyaram, T.Geethakrishnan, Study of Third-Order Nonlinear Optical Properties of Undoped and Dye Doped 1, 7, 7-Trimethylbicyclo [2.2.1] Heptan-2-OneUsing Z-Scan Technique IOSR Journal of Engineering (IOSRJEN) ISSN (e): 2250-3021 , ISSN (p): 2278-8719PP 25-29

[34]. S. Jeyaram, T. Geethakrishnan Low power laser induced NLO properties and optical limiting of an anthraquinone dye using Z-scan technique J Mater Sci: Mater Electron (2017) 28:98209827DOI 10.1007/s10854-017-6736-6

[36]. S.Ramakanth, S.Hamad, S.Venugopal Rao and K.C.J.Raju, AIP Ad., 2015, 5, 057139.

[37]. M.Saravanan, T.C.Sabari Girisun, G.Vinitha and S.Venugopal Rao, RSC Adv., 23016, 6, 91083. 


\section{Figures}

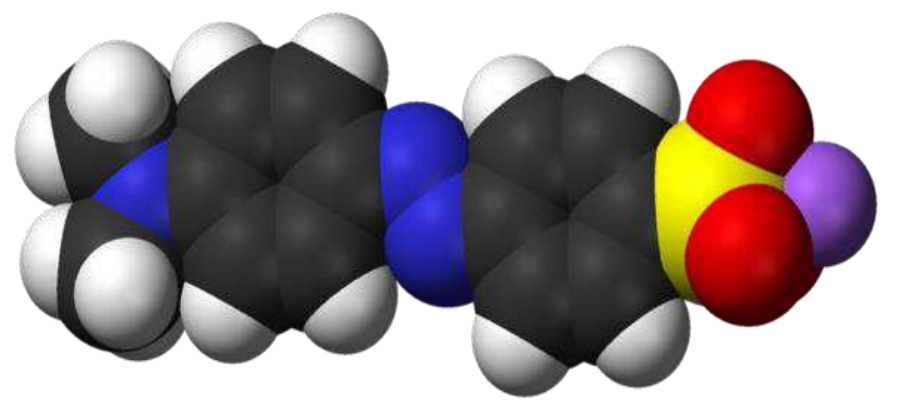

Fig.1 Molecular Structure of Methyl Orange

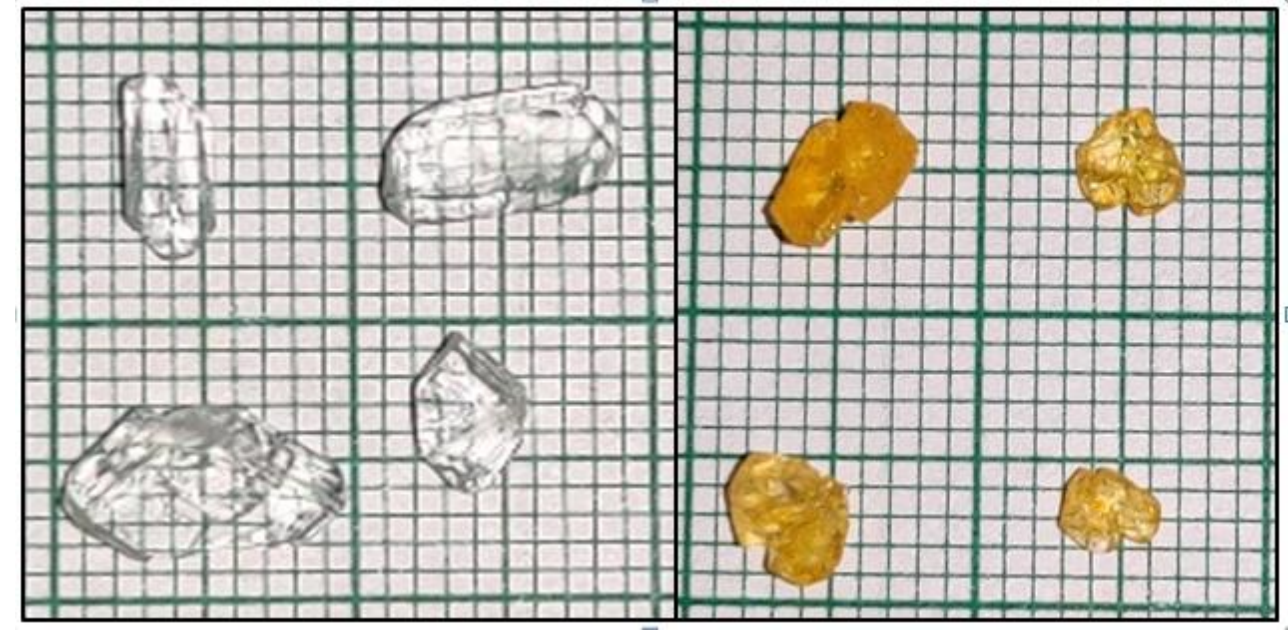

Fig.2 (a) Pure (b) MO doped PPB crystals 


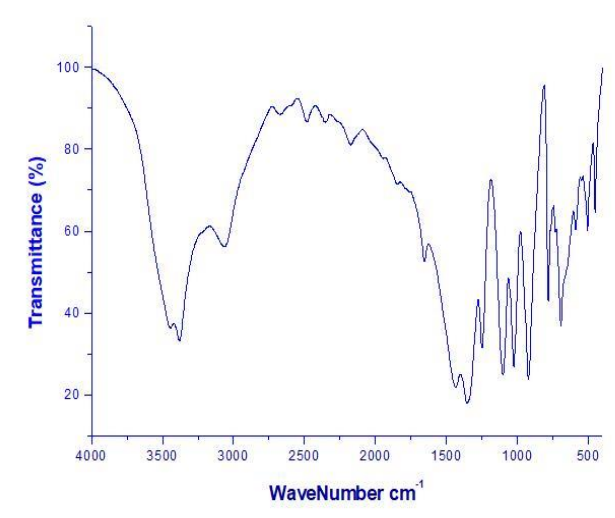

(a)

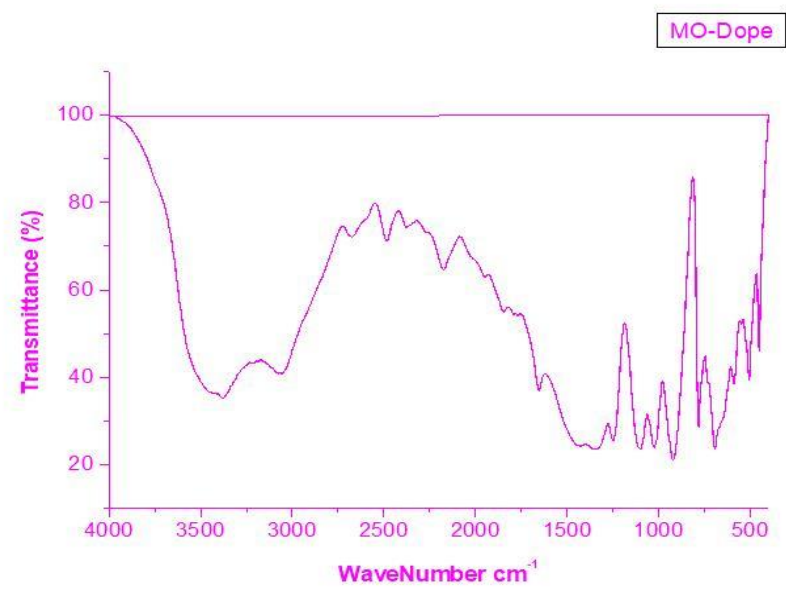

(b)

Fig. 3 FTIR Spectra of (a) pure and (b) MO Doped PPB

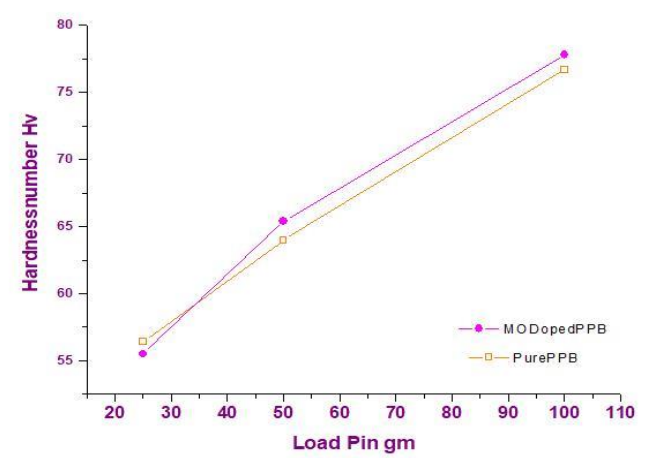

(a)

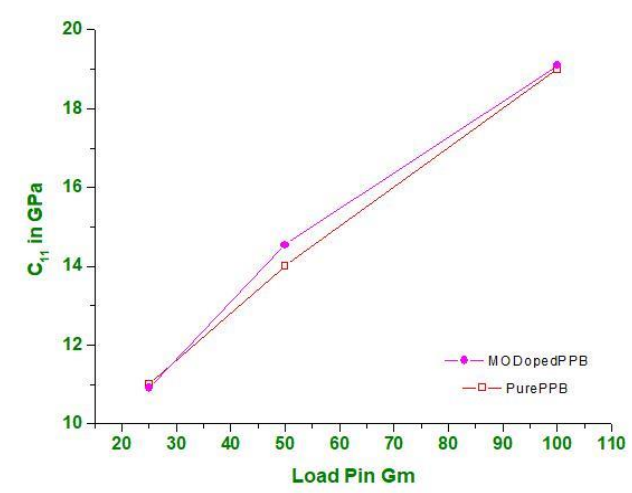

(b)

Fig. 4 (a) Hardness Number and (b) Stiffness constant plots for pure PPB and MOPPB 


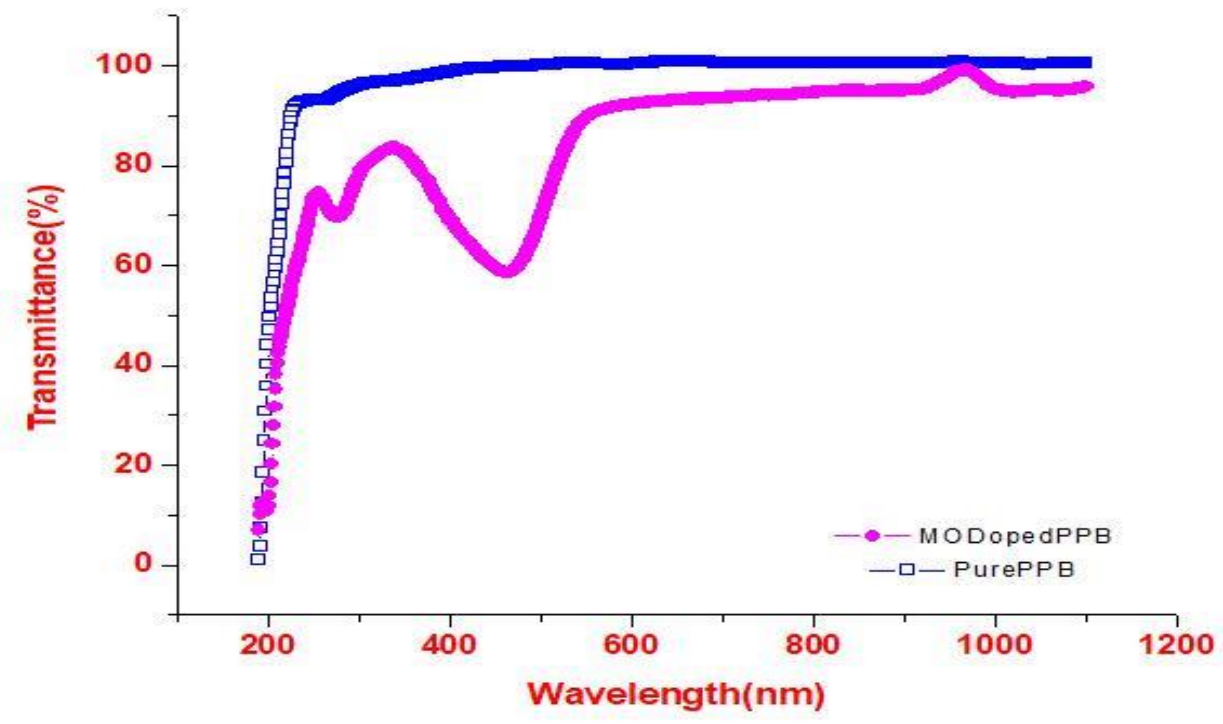

Fig. 5 Optical Transmission spectrum of pure and MO doped PPB
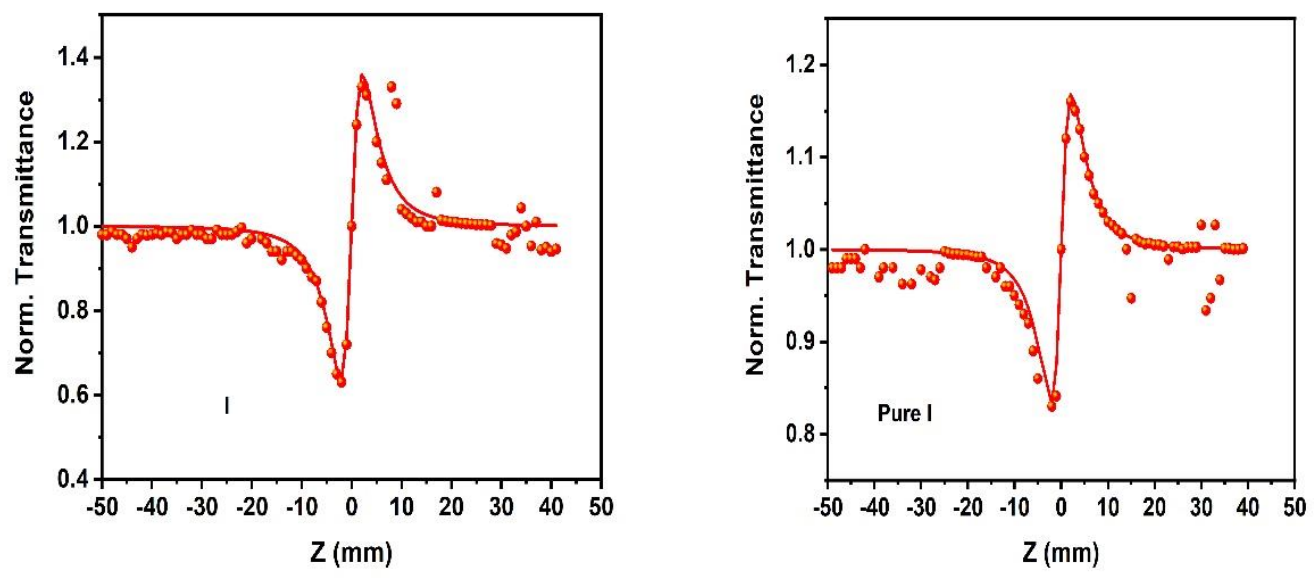

Fig.6 Closed Aperture Mode of MOPPB and Pure PPB 

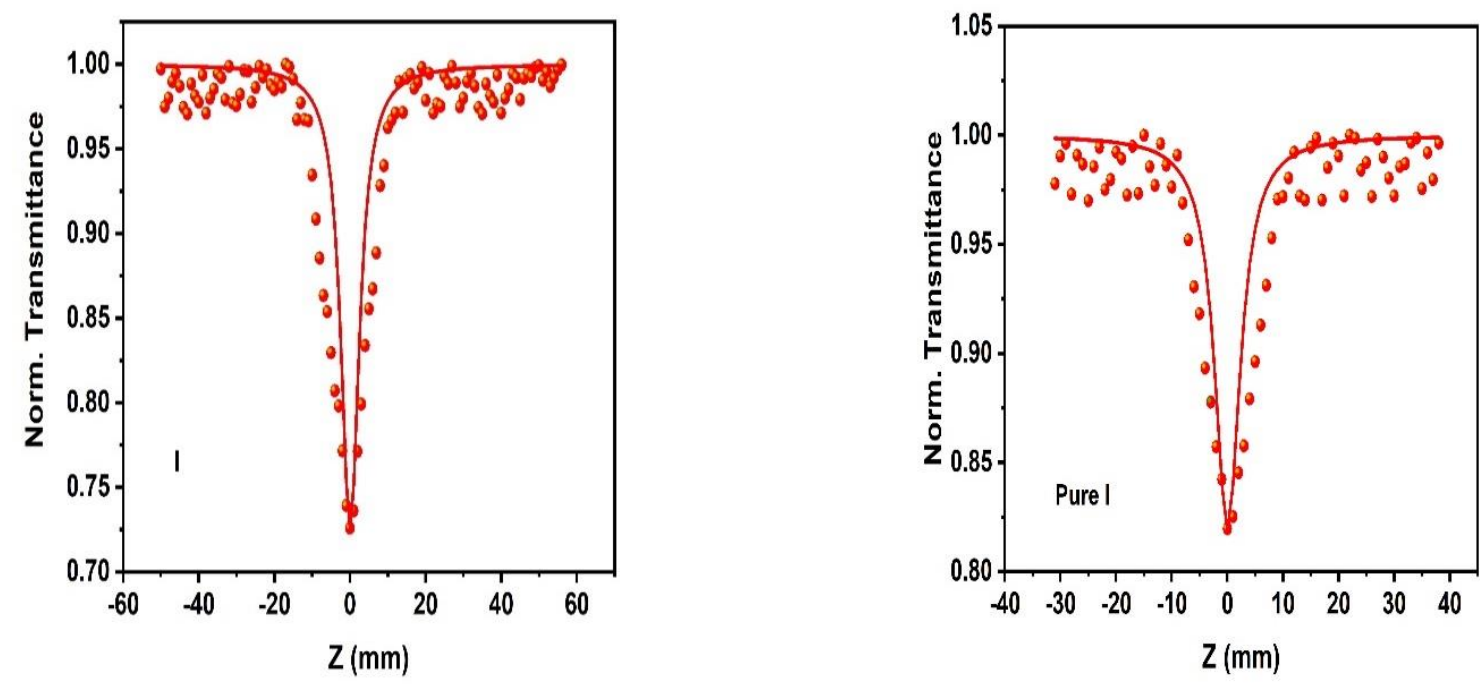

Fig.7. Open Aperture Mode of MOPPB and Pure PPB
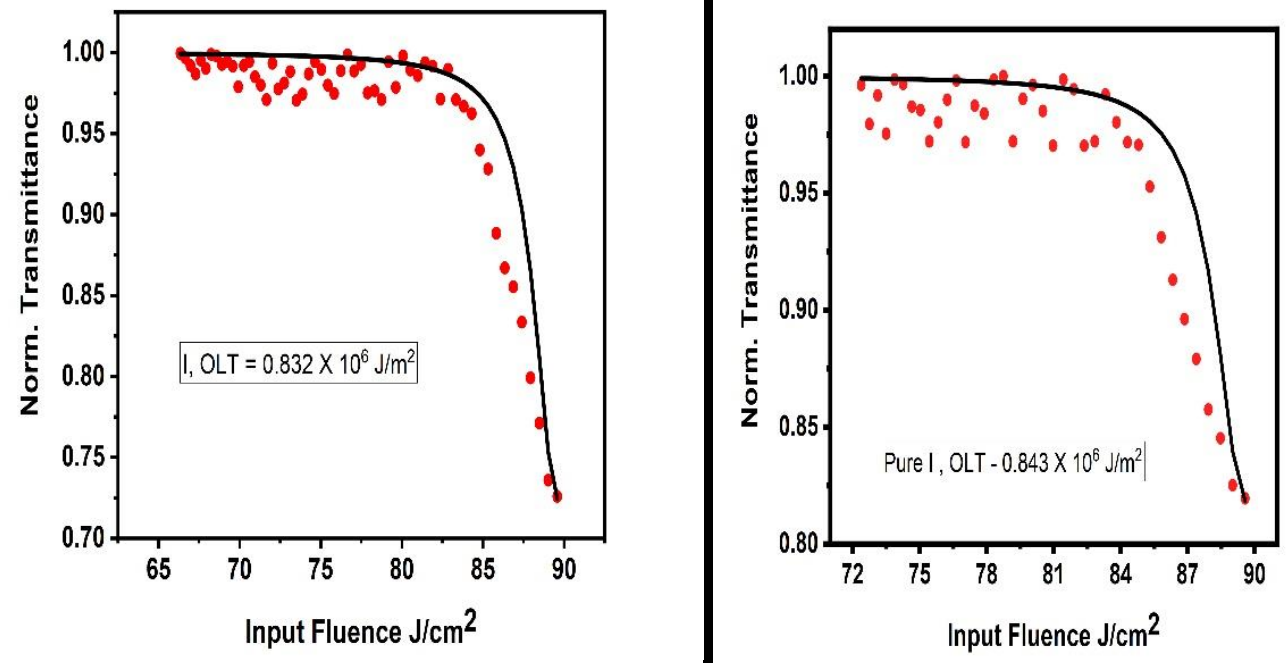

Fig.8 Optical Limiting Behaviour of MOPPB and pure PPB 
Tables

Table 1: Single crystal XRD Data

\begin{tabular}{|l|l|l|}
\hline & Pure PPB & MOPPB \\
\hline Unit cell paramaters & $\mathrm{a}=9.05 \AA, \mathrm{b}=11.17 \AA, \mathrm{c}=11.06 \AA$ & $\mathrm{a}=9.09 \AA, \mathrm{b}=11.20 \AA, \mathrm{c}=11.12 \AA$ \\
\hline Crystal Structure & orthorhombic & Orthorhombic \\
\hline Volume & $1120 \AA^{3}$ & $1132 \AA^{3}$ \\
\hline
\end{tabular}

Table 2: Spectral band assignments of MO doped PPB crystals

\begin{tabular}{|l|l|}
\hline Wavenumber $\left.\mathbf{( c m}^{-1}\right)$ & Spectral band assignments \\
\hline 3444 & Asymmetric N-H stretching \\
2669 & O-H stretching vibrations \\
1844 & C-H stretching vibrations \\
1434 & CO band stretching vibrations \\
1358 & Symmetric stretching vibrations of C-H \\
1250 & C-N in plane deformation \\
1102 & Deformation mode of CH3 \\
924 & C-C stretching vibrations \\
782 & B-O stretching mode \\
508 & N-H wagging \\
& O-B-O ring bending \\
\hline
\end{tabular}


Table 3 Input laser parameters

\begin{tabular}{|l|l|}
\hline Various Input Parameters & Values \\
\hline Laser Type & CW Laser \\
\hline Wavelength of the laser $(\boldsymbol{\lambda})$ & $785 \mathrm{~nm}$ \\
\hline Peak power & $50 \mathrm{~mW}$ \\
\hline Focal length of the lens (f) & $10 \mathrm{~cm}$ \\
\hline Diameter of the laser beam $(\mathrm{d})$ & $0.1 \mathrm{~cm}$ \\
\hline Thickness of the sample $(\mathrm{L})$ & $0.1 \mathrm{~cm}$ \\
\hline Beam Waist $\left(\boldsymbol{\omega}_{\mathrm{o}}\right)$ & $2.498 \times 10^{-3} \mathrm{~cm}$ \\
\hline Intensity of the laser beam $\left(\mathrm{I}_{\mathrm{o}}\right)$ & $2.155 \mathrm{KW} / \mathrm{cm}^{2}$ \\
\hline Aperture Radius $\left(\mathrm{r}_{\mathrm{o}}\right)$ & $3 \mathrm{~mm}$ \\
\hline Spot Size at the aperture $\left(\boldsymbol{\omega}_{\mathrm{o}}\right)$ & $0.5 \mathrm{~cm}$ \\
\hline
\end{tabular}

Table 4: Calculated Third order NLO Parameters for pure PPB and MOPPB

\begin{tabular}{|l|l|l|}
\hline Third Order NLO Coefficient & Pure PPB & MOPPB \\
\hline Nonlinear absorption coefficient $(\boldsymbol{\beta})$ & $0.98 \times 10^{-5} \mathrm{~m} / \mathrm{W}$ & $1.68 \times 10^{-5} \mathrm{~m} / \mathrm{W}$ \\
\hline Nonlinear refractive index $\left(\mathrm{n}_{2}\right)$ & $4.62 \times 10^{-12} \mathrm{~m}^{2} / \mathrm{W}$ & $10.2 \times 10^{-12} \mathrm{~m}^{2} / \mathrm{W}$ \\
\hline Real part NLO susceptibility, $\operatorname{Re}\left(\boldsymbol{\chi}^{(3)}\right)$ & $5.9 \times 10^{-10} \mathrm{~m}^{2} / \mathrm{V}^{2}$ & $13.2 \times 10^{-10} \mathrm{~m}^{2} / \mathrm{V}^{2}$ \\
\hline Imaginary part NLO susceptibility, $\operatorname{Im}\left(\boldsymbol{\chi}^{(3)}\right)$ & $3.4 \times 10^{-9} \mathrm{~m}^{2} / \mathrm{V}^{2}$ & $5.9 \times 10^{-9} \mathrm{~m}^{2} / \mathrm{V}^{2}$ \\
\hline Susceptibility $\left(\boldsymbol{\chi}^{(3)}\right)$ & $3.5 \times 10^{-9} \mathrm{~m}^{2} / \mathrm{V}^{2}$ & $6.1 \times 10^{-9} \mathrm{~m}^{2} / \mathrm{V}^{2}$ \\
\hline OL Threshold & $0.843 \times 10^{-6} \mathrm{~J} / \mathrm{m}^{2}$ & $0.832 \times 10^{-6} \mathrm{~J} / \mathrm{m}^{2}$ \\
\hline
\end{tabular}


Figures

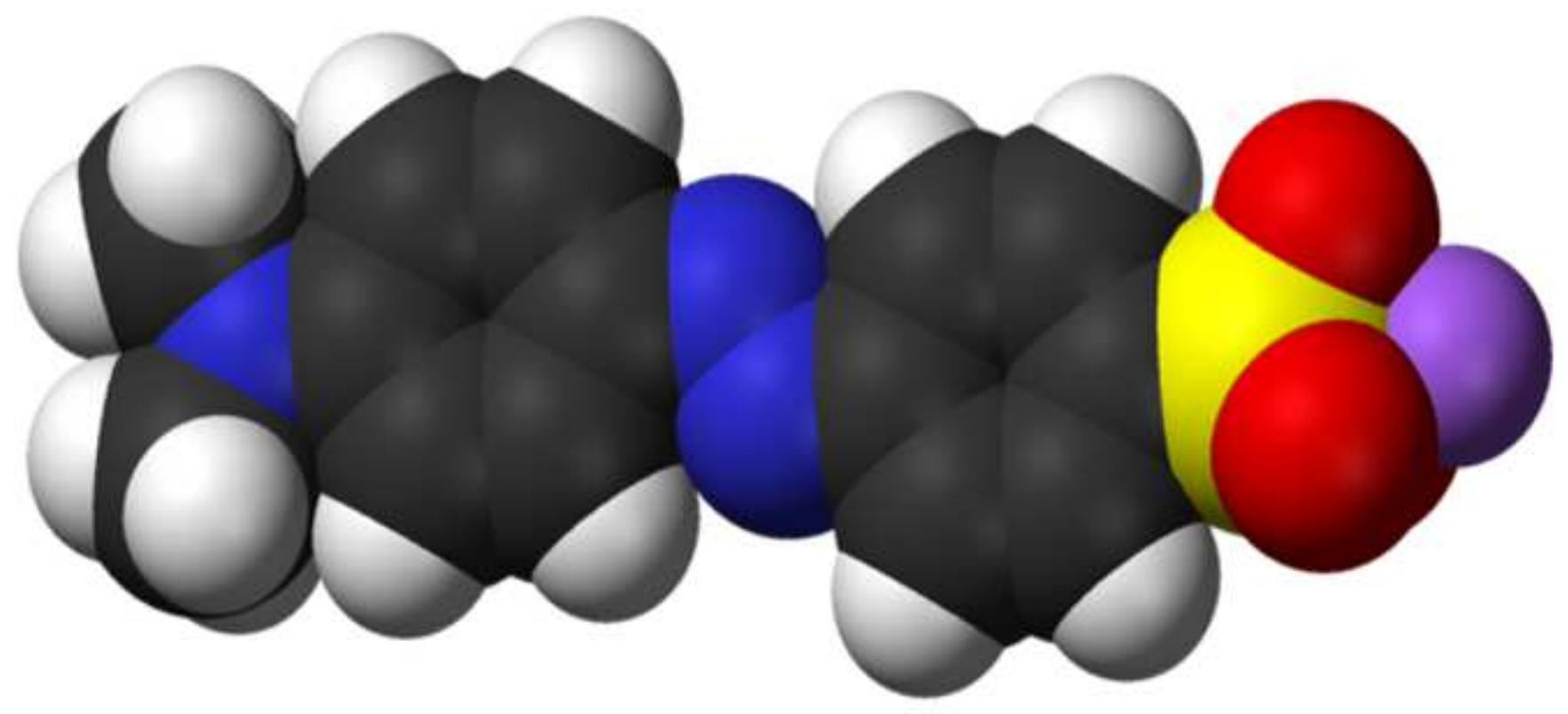

Figure 1

Molecular Structure of Methyl Orange

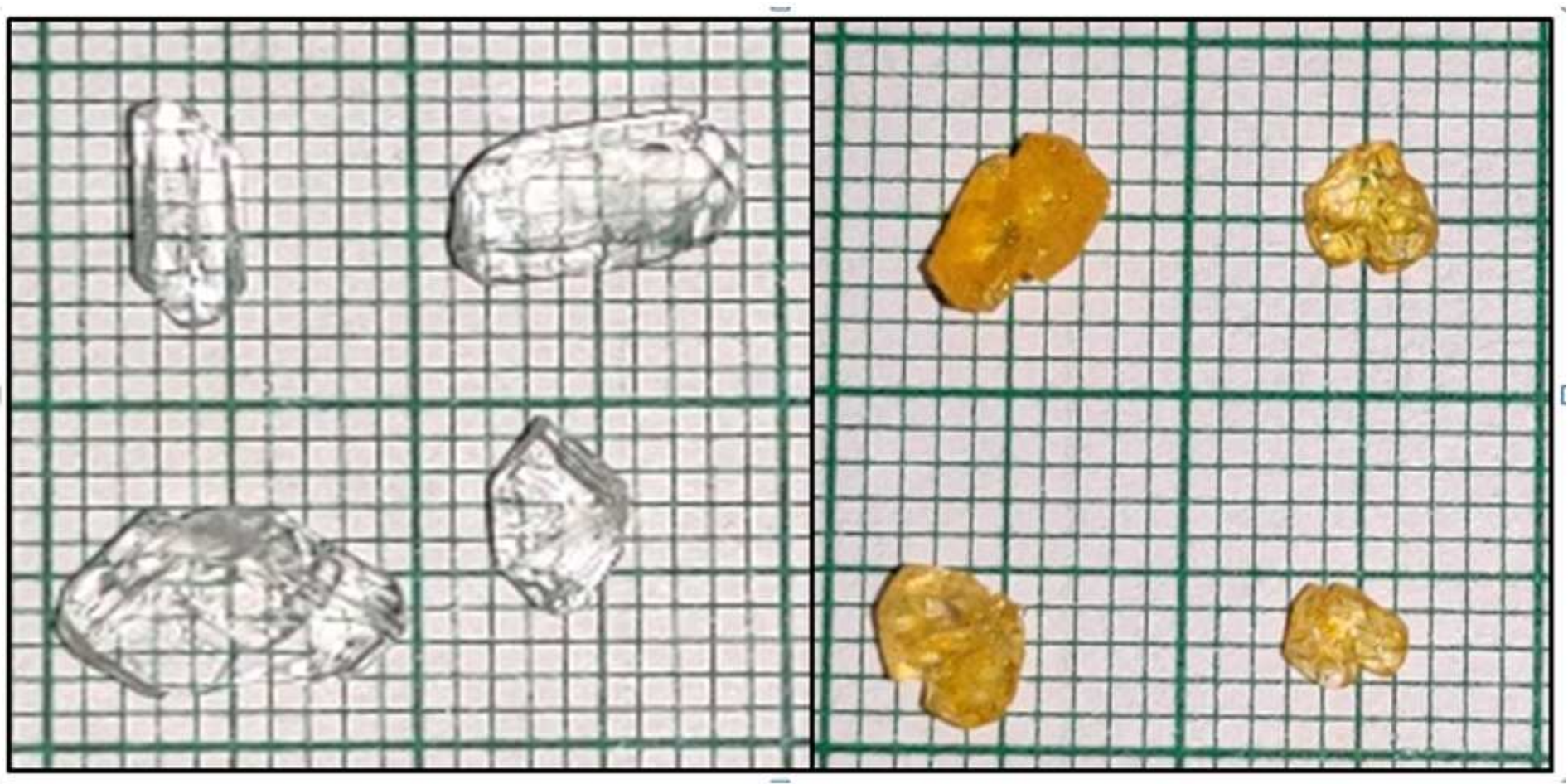

Figure 2

(a) Pure (b) MO doped PPB crystals 


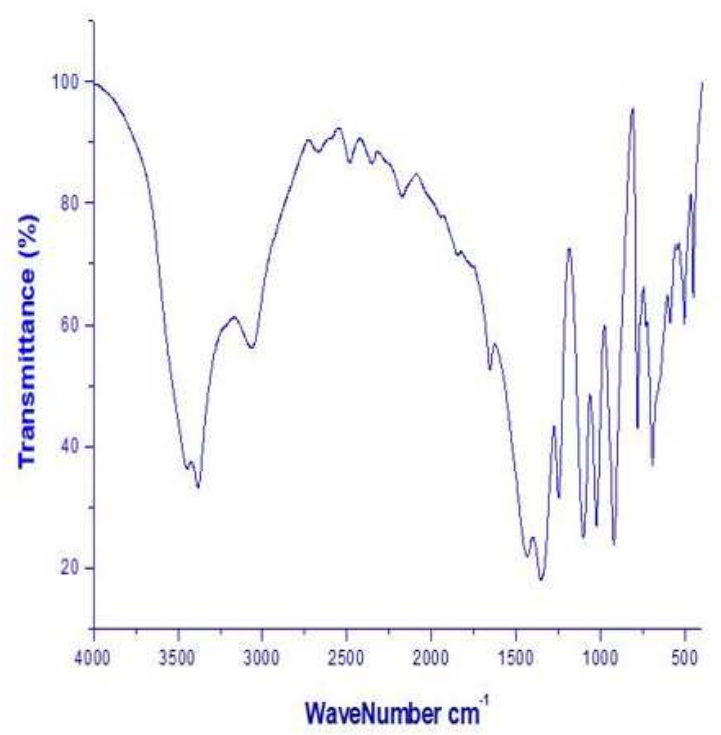

(a)

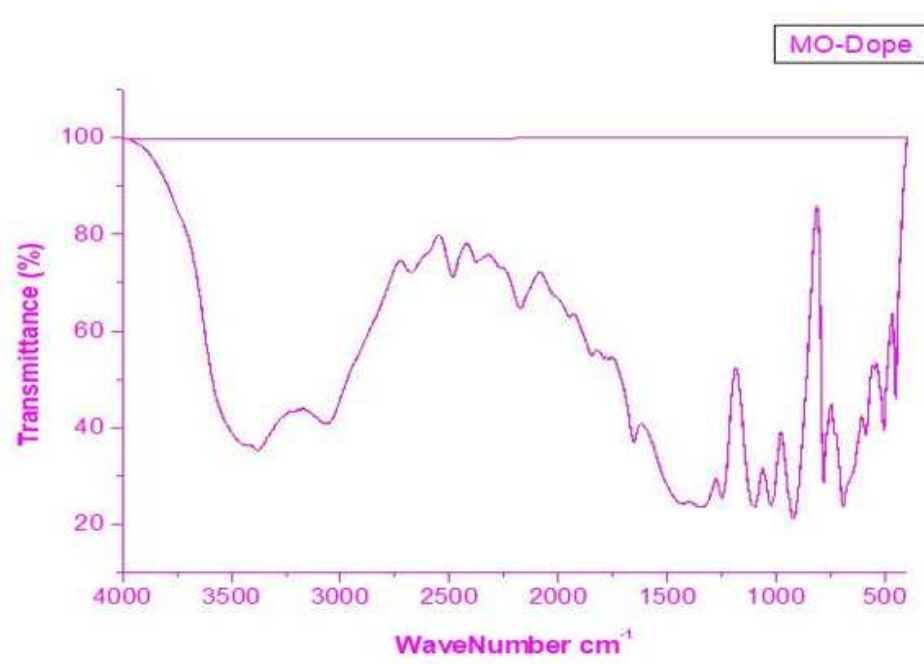

(b)

\section{Figure 3}

FTIR Spectra of (a) pure and (b) MO Doped PPB

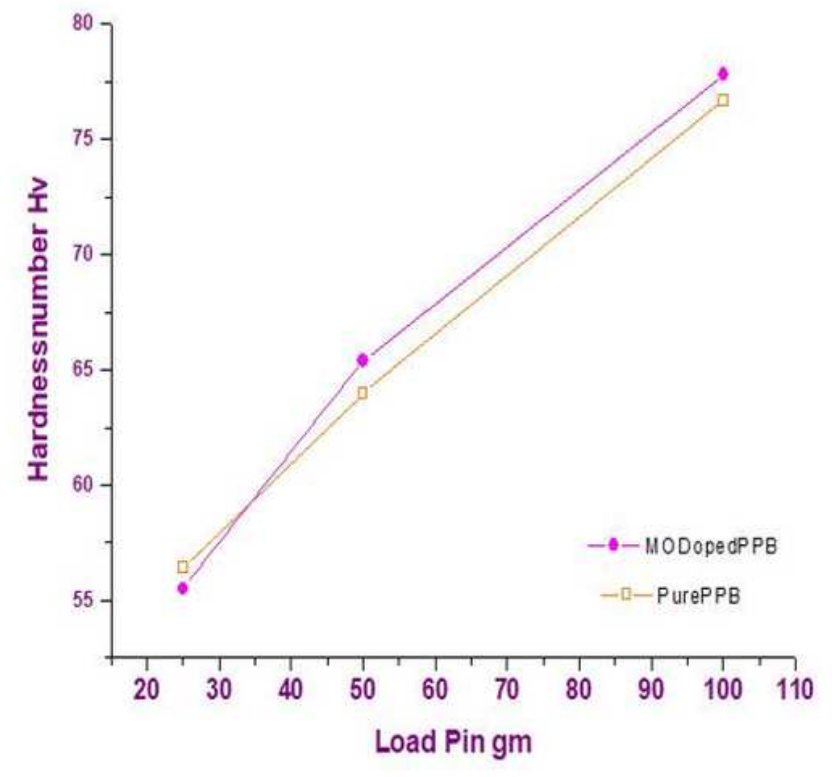

(a)

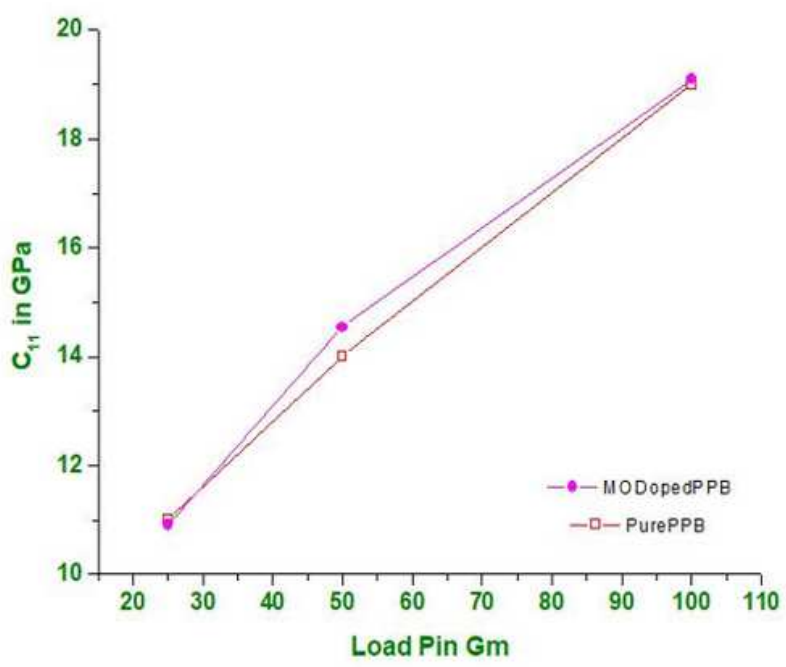

(b)

Figure 4

(a) Hardness Number and (b) Stiffness constant plots for pure PPB and MOPPB 


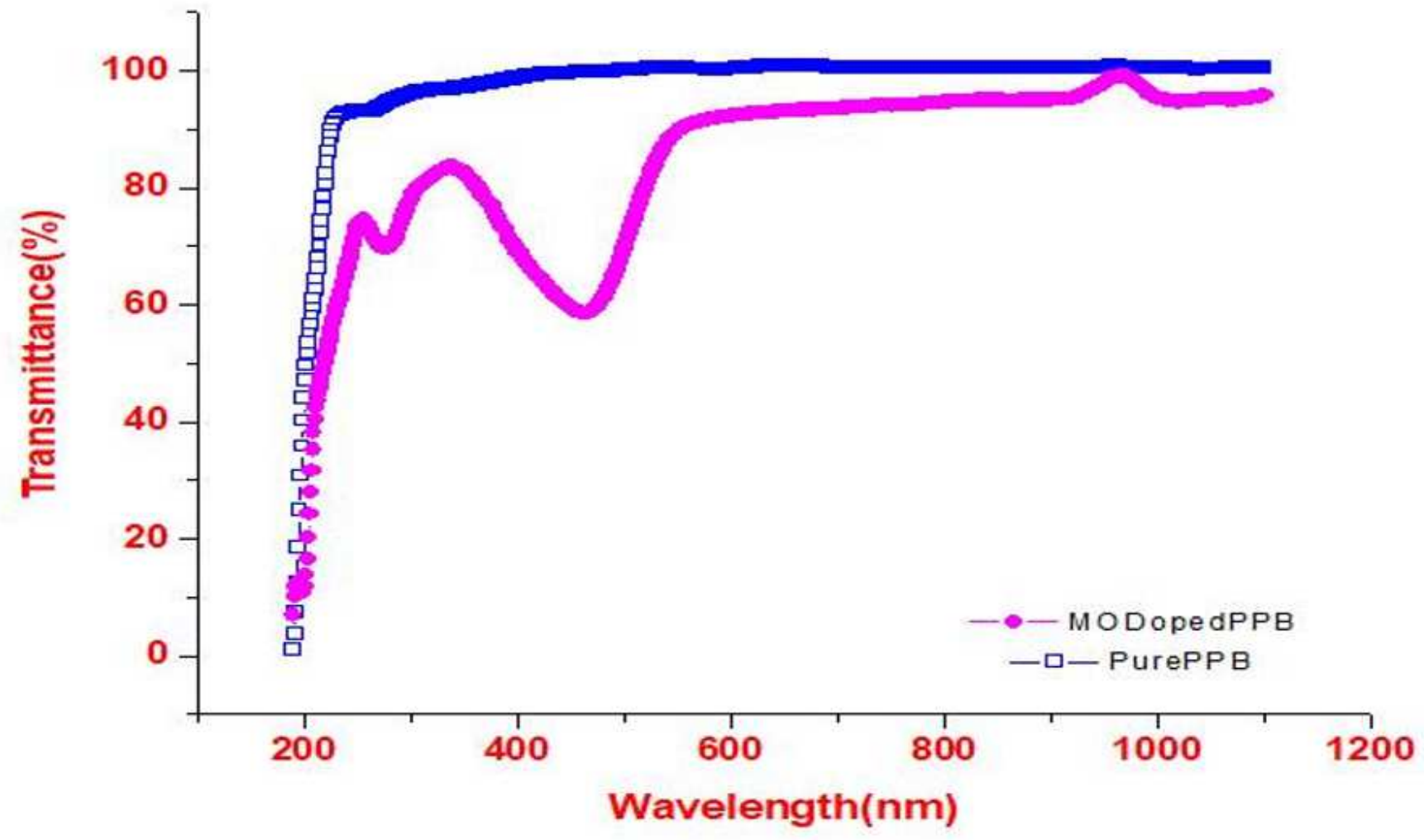

Figure 5

Optical Transmission spectrum of pure and MO doped PPB

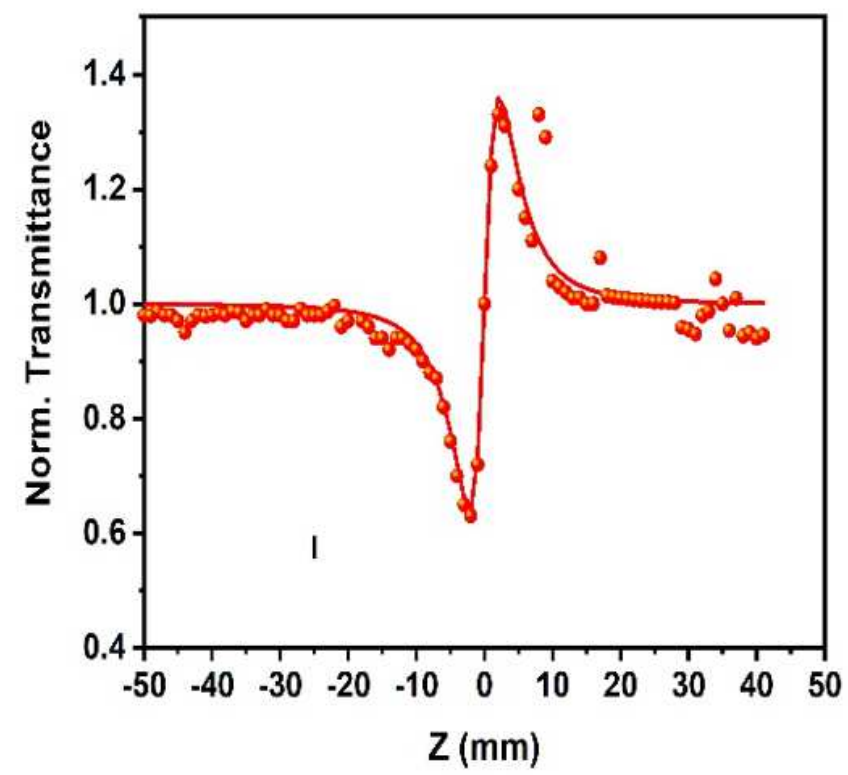

(a)

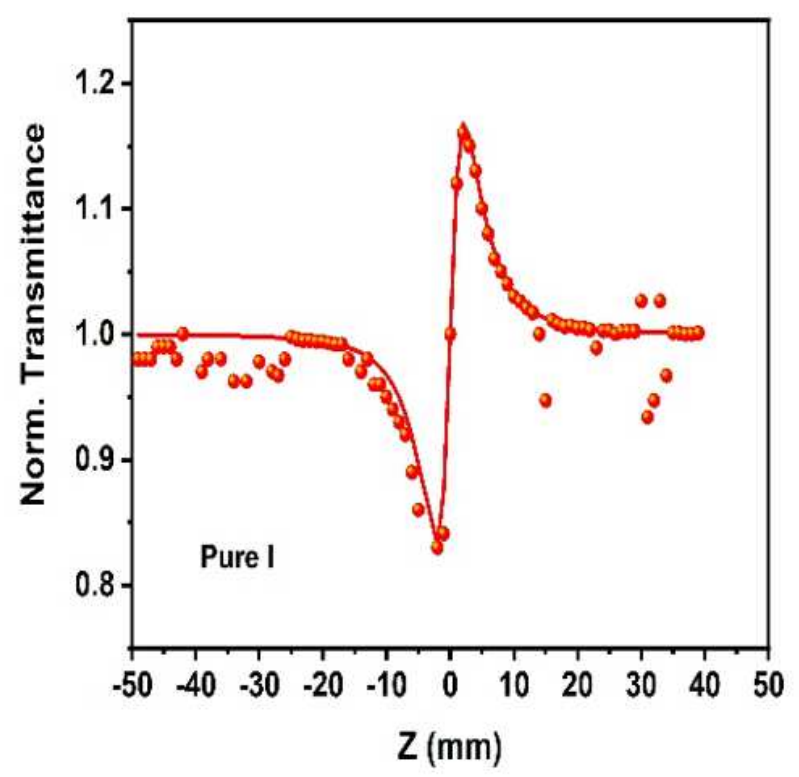

(b)

Figure 6

Closed Aperture Mode of MOPPB and Pure PPB 

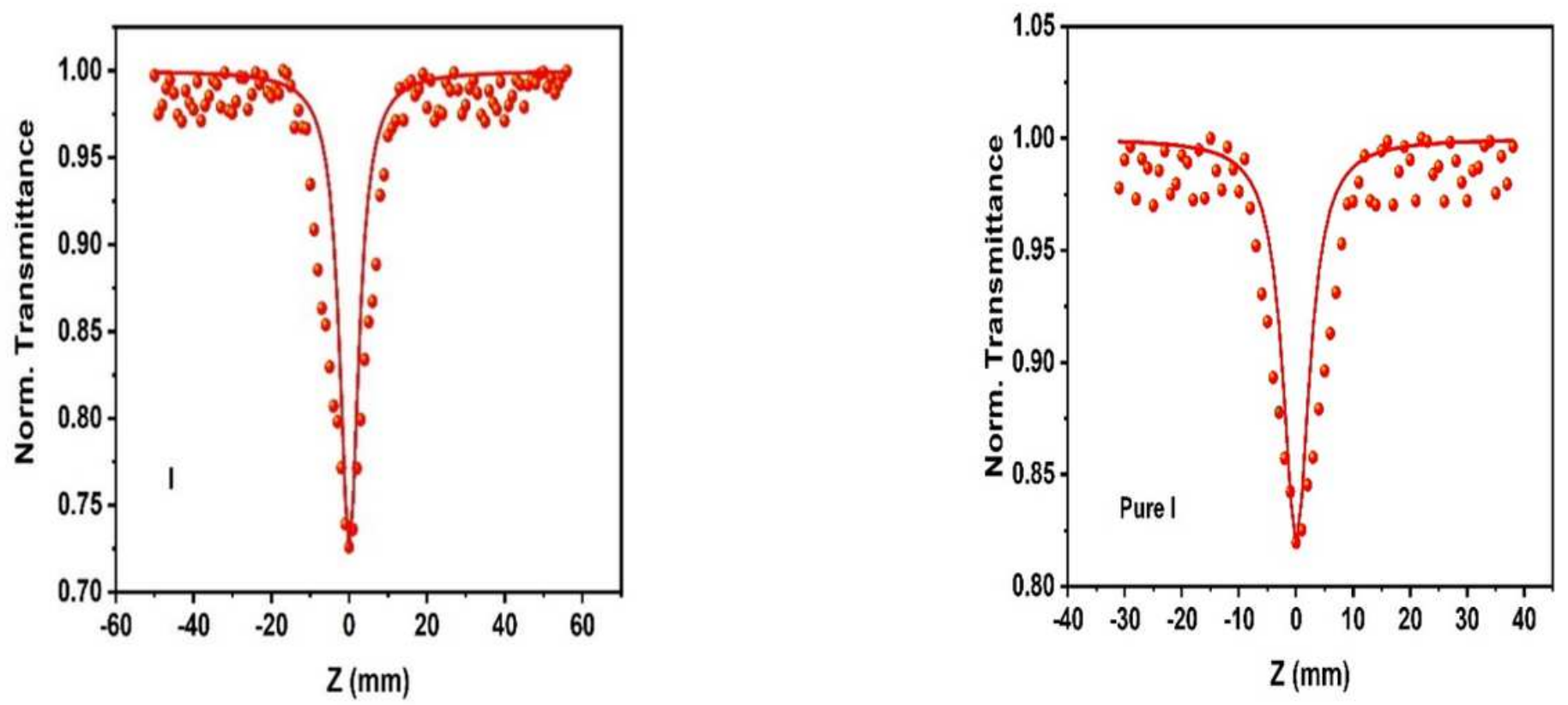

Figure 7

Open Aperture Mode of MOPPB and Pure PPB
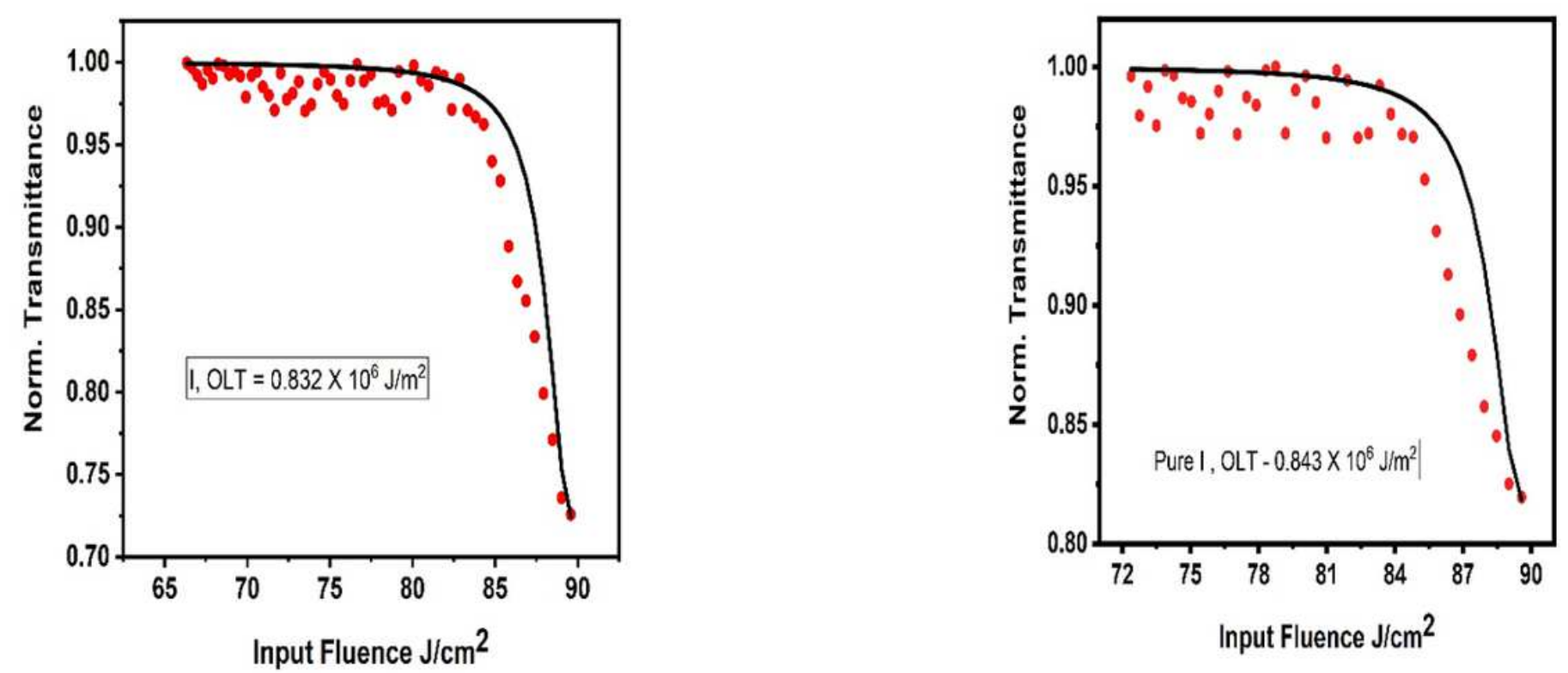

Figure 8

Optical Limiting Behaviour of MOPPB and pure PPB 